\title{
Effects of a sub-lethal copper exposure on non-green Acer pseudoplatanus cell lipids
}

\author{
Mário Pádua a ${ }^{\mathrm{a}, \mathrm{b}, *}$, Serge Aubert ${ }^{\mathrm{a}}$, Adalcina Casimiro ${ }^{\mathrm{b}}$, Richard Bligny ${ }^{\mathrm{a}}$, Maryse A. Block ${ }^{\mathrm{a}}$ \\ ${ }^{a}$ Laboratoire de Physiologie Cellulaire Végétale, CNRS (UMR 5019), DRDC, CEA-Grenoble, 17, rue des Martyrs, 38054 Grenoble cedex 9, France \\ ${ }^{b}$ Centro de Engenharia Biológica, DBV, Faculdade de Ciências da Universidade de Lisboa, Bloco C-2, Campo Grande, 1700 Lisbon, Portugal
}

Received 8 October 2002; accepted 27 January 2003

\begin{abstract}
Non-green sycamore cells (Acer pseudoplatanus L.) treated with $50 \mu \mathrm{M} \mathrm{Cu}^{2+}$ showed a reversible arrest of cell growth after $5 \mathrm{~d}$, indicating that the concentration used was sub-lethal for the cells. Growth arrest was accompanied by hexose and nucleotide-phosphate accumulation and, in contrast with previous reports, no polar-lipid degradation was found. Sub-lethal $\mathrm{Cu}^{2+}$ exposure resulted in an increase in phospholipid amounts, mostly due to an increase of phosphatidylethanolamine. Although the total amount of glycolipids was not significantly changed, $\mathrm{Cu}^{2+}$ exposure changed the relative concentrations of monogalactosyldiacylglycerol (MGDG), digalactosyldiacylglycerol (DGDG) and sulphoquinovosyldiacylglycerol (SQDG). There was a marked increase of DGDG whereas MGDG and SQDG declined. Our results suggest an increase of DGDG synthesis through a pathway similar to the recently described DGD2 pathway and an inhibition of SQDG synthesis. Furthermore, we observed modifications of fatty acid composition of the plastid synthesised lipids. A significant increase in linoleate (18:2) and a decrease in linolenate (18:3) were found in MGDG, DGDG, SQDG and phosphatidylglycerol (PG), reflecting a deficient desaturation of plastid-located 18:2 fatty acids. In SQDG and PG, $\mathrm{Cu}^{2+}$ treatment also induced a strong enrichment of palmitate (16:0). The effects of $\mathrm{Cu}^{2+}$ on DGDG synthesis and fatty acid desaturation are discussed.
\end{abstract}

(C) 2003 Éditions scientifiques et médicales Elsevier SAS. All rights reserved.

Keywords: Acer pseudoplatanus; Copper; Metabolism; Membrane lipids; Sub-lethal stress

\section{Introduction}

Copper is an essential microelement for plants [30], involved in metabolism as cofactor of various proteins with important functions such as superoxide dismutase, polyphenol oxidase, cytochrome oxidase and plastocyanin. When in excess, this cation can become highly toxic. Phytotoxic amounts of $\mathrm{Cu}^{2+}$ most frequently originate from urban, in-

Abbreviations: ACP, acyl carrier protein; DAG, diacylglycerol; DGDG, digalactosyldiacylglycerol; DPG, cardiolipin; MGDG, monogalactosyldiacylglycerol; P-, phosphoryl; PC, phosphatidylcholine; PE, phosphatidylethanolamine; PG, phosphatidylglycerol; PI, phosphatidylinositol; SQDG, sulphoquinovosyldiacylglycerol; GPC, glycerophosphocholine; GPE, glycerophosphoethanolamine; GPG, glycerophosphoglycerol; GPI, glycerophosphoinositol; PGA, glycerate-3P; lyso-PC, lyso-phosphatidylcholine; 16:0, palmitate; $18: 0$, stearate; $18: 1$, oleate; $18: 2$, linoleate; $18: 3$, linolenate.

* Corresponding author. Present address: Escola Superior de Tecnologia de Saúde de Lisboa, Av. D. João II, Lt 4.69.01, Parque das Nações 1990-096 Lisbon, Portugal.

E-mail address: mpadua@fc.ul.pt (M. Pádua). dustrial (smelters) and agricultural (cupric fungicide treatments) activities. At the level of whole plants, excess $\mathrm{Cu}^{2+}$ is known to inhibit growth and photosynthesis, the thresholds of toxicity being dependent on the plant species [9,14,25] Due to their high potential to generate free radicals, high concentrations of $\mathrm{Cu}^{2+}$ are known to trigger oxidative damage and alteration of cell membrane properties by peroxidation of lipids [17,25,26,32,33] resulting in a decline of lipid contents. However, little is known about the specific effects of $\mathrm{Cu}^{2+}$ on lipid metabolism. When plants were supplied hydroponically with excess $\mathrm{Cu}^{2+}$, decline of monogalactosyldiacylglycerol (MGDG) content in thylakoids was described [15,16] Similar MGDG decrease in presence of other heavy metals such as $\mathrm{Cd}^{2+}$ or $\mathrm{Pb}^{2+}$ was attributed to an increase of galactolipase activity [27,31] Reports of effects of $\mathrm{Cu}^{2+}$ on other lipids were contradictory. Ouariti et al.[20] found that all polar lipids decreased in $\mathrm{Cu}^{2+}$-treated Lycopersicon esculentum roots and leaves. Conversely, in thylakoid membranes from Spinacia oleracea, Maksymiec et al. [15] reported a decrease of MGDG and an increase of digalacto- 
syldiacylglycerol (DGDG), sulphoquinovosyldiacylglycerol (SQDG), phosphatidylcholine (PC) and of the most typical plastid phospholipid, also occurring in other membranes, phosphatidylglycerol (PG). In addition, Maksymiec et al. [16] described lower contents of MGDG, PG and PC and slightly higher contents of DGDG and SQDG in the roots of Phaseolus coccineus. Increased levels of palmitate (16:0) compared to stearate (18:0) and decreased unsaturated derivatives of 18:0 were also reported in brown algae in the presence of elevated $\mathrm{Cu}^{2+}$, presumably resulting from a change in acyl-ACP transferase activities [28,29]. Similar results have been reported in higher plants, however attributing the phenomenon to $\mathrm{Cu}^{2+}$-derivated lipid peroxidation, lipooxygenase or lipid deacylase activities [7,14]

Using sycamore (Acer pseudoplatanus L.) cell suspension, a model permitting the control of culture conditions, in particular $\mathrm{Cu}^{2+}$ concentrations, we found that sub-lethal $\mathrm{Cu}^{2+}$ concentrations $(50 \mu \mathrm{M})$ strongly induce mitochondrial alternative oxidase and reduce cell respiration due to the arrest of mitochondrial biogenesis [21,22]

In the present work, we use the same non-green cell suspension model to further analyse the effect of a sub-lethal $\mathrm{Cu}^{2+}$ concentration on soluble phosphorylated metabolites and on membrane lipids. We report that sub-lethal $\mathrm{Cu}^{2+}$ excess does not result in lipid degradation and we show a decline of MGDG and a concomitant increase of DGDG. The effects of $\mathrm{Cu}^{2+}$ on DGDG synthesis and fatty acid desaturation are discussed.

\section{Results}

\subsection{Effects of copper concentration on cell growth}

In order to analyse the effects of excess $\mathrm{Cu}^{2+}$ in plants it is of particular importance to establish the conditions of sublethality. Fig. 1 shows that $50 \mu \mathrm{M} \mathrm{Cu}^{2+}$ resulted in growth arrest after $5 \mathrm{~d}$ of treatment, as demonstrated by the arrest of both fresh and dry wt. Cell density was maintained for $12 \mathrm{~d}$ and growth could be reinitiated at any time with a $48 \mathrm{~h}$ lag phase after removing $\mathrm{Cu}^{2+}$ from the culture medium by extensive washing with fresh control medium. In contrast, growth was immediately stopped in cells treated with 100 $\mu \mathrm{M} \mathrm{Cu}^{2+}$ and cell death occurred within $3 \mathrm{~d}[21]$. From these results and those previously reported [21,22] we considered that sub-lethal conditions were obtained when cells were exposed to $50 \mu \mathrm{M} \mathrm{Cu}^{2+}$ for $5 \mathrm{~d}$.

\subsection{Metabolite analysis}

Starch and soluble metabolites were analysed using biochemical methods and ${ }^{31} \mathrm{P}-\mathrm{NMR}$ to assess the overall state of cell metabolism at the fifth day of $50 \mu \mathrm{M} \mathrm{Cu}^{2+}$ exposure. Consistent with growth arrest, the results in Table 1 shows that sucrose, glucose and fructose as well as hexose-P and their derivatives (glucose-6P, frutose-6P, mannose-6P, UDPglucose and UDP-galactose) accumulated in $\mathrm{Cu}^{2+}$-treated

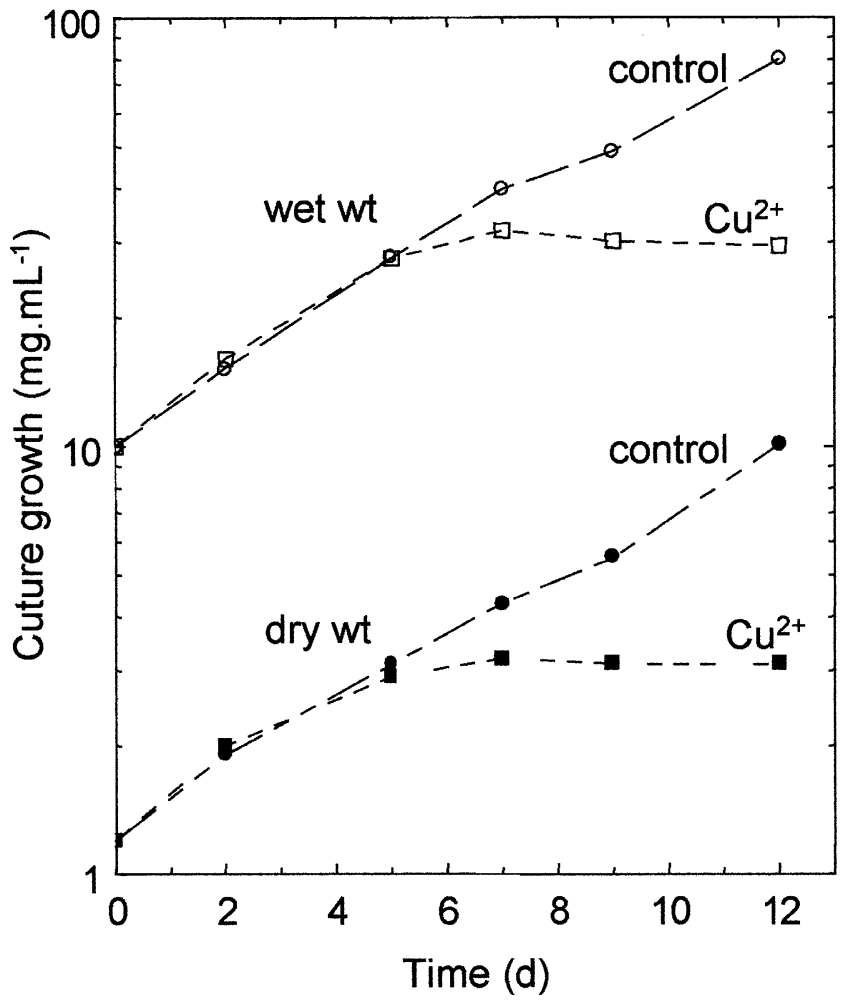

Fig. 1. Effect of copper on sycamore cells growth. At different times following sub-culturing, cells were harvested and the cell wet wt measured in

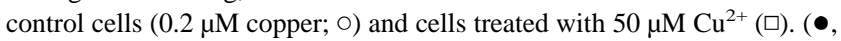
-), time evolution of dry wt: control, $(0.2 \mu \mathrm{M}$ copper, $\bullet) ; 50 \mu \mathrm{M} \mathrm{Cu}^{2+}(\mathbf{\bullet})$. Vertical axis is in logarithmic units. Results are the median of five independent experiments with less than $10 \%$ deviation.

cells, while the levels of ATP and NAD(P) did not change significantly. Interestingly, no significant changes were noted in the starch Table 1).

Table 1 also shows the marked decline of cell concentrations of the phosphodiesters glycerophosphocholine (GPC), glycerophosphoglycerol (GPG), glycerophosphoinositol (GPI). The role of these compounds in plant metabolism is still unclear, but they are possible intermediates in phospholipid turnover (synthesis and/or degradation). In this context, our results also show that phosphocholine and phosphoethanolamine, two markers of autophagic phospholipid degradation [3], do not accumulate in cells treated with $50 \mu \mathrm{M} \mathrm{Cu}^{2+}$, while they accumulate, respectively, to 320 and $115 \mathrm{nmol} \mathrm{g}^{-1}$ wet wt, at the lethal concentration of $100 \mu \mathrm{M} \mathrm{Cu}^{2+}$.

These results prompted us to further analyse the effects of sub-lethal $\mathrm{Cu}^{2+}$ on cell polar lipids and their fatty acids on fifth day of $\mathrm{Cu}^{2+}$ treatment.

\subsection{Membrane lipids}

\subsubsection{Polar lipid composition}

The cells exposed to $50 \mu \mathrm{M} \mathrm{Cu}^{2+}$ for $5 \mathrm{~d}$ showed a 9.5\% increase of polar lipid mass on a fresh wt basis Table 2. Being under $10 \%$, this increase was considered nonsignificant and reflected mainly the small increase in phospholipid (10.5\%) amount whereas the glycolipid amount 
Table 1

Enzymatic determination of soluble sugars and starch and ${ }^{31} \mathrm{P}-\mathrm{NMR}$ quantification of several metabolites of A. pseudoplatanus cells submitted for $5 \mathrm{~d}$ to $0.2 \mu \mathrm{M}$ (control) and $50 \mu \mathrm{M} \mathrm{Cu}^{2+}$. We also quantified the phosphocholine and phosphoethanolamine of cells treated with $100 \mu \mathrm{M} \mathrm{Cu}^{2+}$ for $2 \mathrm{~d}$ obtaining 320 and $115 \mathrm{nmol} \mathrm{g}^{-1}$ wet wt, respectively. Results are the median of five independent experiments with less than $10 \%$ deviation. The data ranges of the five independent experiments are referred in brackets. nd, nondetected

\begin{tabular}{lll}
\hline & \multicolumn{2}{l}{ Metabolite $\left(\mathrm{nmol} \mathrm{g}^{-1}\right.$ wet wt $)$} \\
& Control & $50 \mu \mathrm{M} \mathrm{Cu}^{2+}$ \\
\hline Sucrose & $55,000(4950)$ & $80,000(6400)$ \\
Glucose & $2000(160)$ & $8000(600)$ \\
Fructose & $1500(129)$ & $3500(315)$ \\
Starch & $40,000(3880)$ & $42,000(3696)$ \\
Glucose-6P & $800(48)$ & $899(58)$ \\
Fructose-6P & $99(8)$ & $145(13)$ \\
Mannose-6P & $215(17)$ & $272(24)$ \\
UDP-glucose & $146(11)$ & $174(13)$ \\
UDP-galactose & $44(4)$ & $69(5)$ \\
Glycerol-3P & $52(5)$ & $54(5)$ \\
ATP & $170(16)$ & $200(15)$ \\
NAD(P) & $43(4)$ & $60(5)$ \\
Gluconate-6P & $15(1)$ & $35(2)$ \\
GPC & $52(4)$ & nd \\
GPE & nd & nd \\
GPG & $64(5)$ & $23(2)$ \\
GPI & $122(10)$ & $37(3)$ \\
Phosphocholine & nd & nd \\
Phosphoethanolamine & nd & nd \\
\hline
\end{tabular}

decreased non-significantly (8\%) Table 2. Among phospholipids, PC and phosphatidylethanolamine (PE) increased in $\mathrm{Cu}^{2+}$-treated cells, with a high increase of PE $(20 \%)$ and a non-significant increase of PC (9\%) Table 2. Phosphatidylinositol (PI) and PG were stable. In contrast, cardiolipin (DPG) mass was markedly reduced by $29 \%$ in agreement with a previous report on mitochondria decline [21]

Although the total amount of glycolipids undertook only a minor decreases, it was of particular interest to observe that $\mathrm{Cu}^{2+}$ exposure triggered a significant alteration of the relative

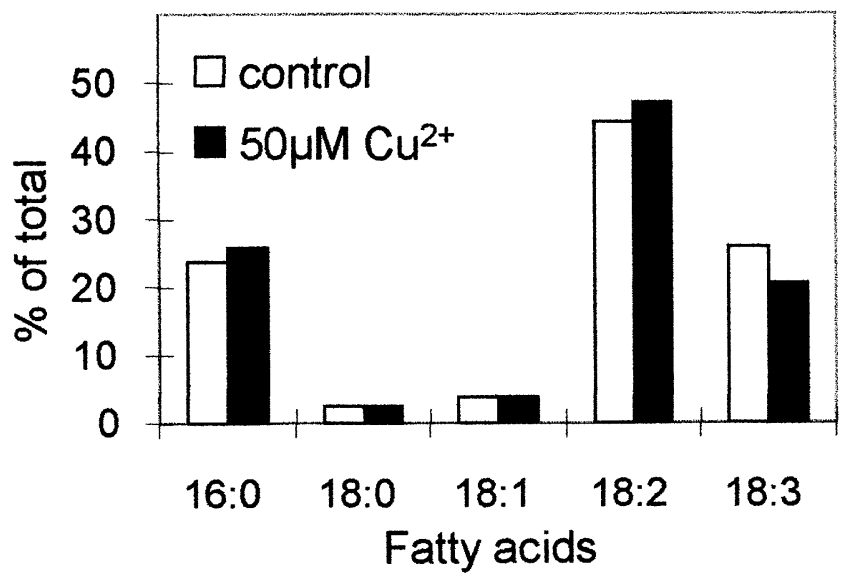

Fig. 2. Total fatty acid content of A. pseudoplatanus cells submitted for $5 \mathrm{~d}$ to $0.2 \mu \mathrm{M}$ (control) and $50 \mu \mathrm{M} \mathrm{Cu}^{2+}$. Results are expressed as percentage of total mass. Results are the median of five independent experiments with less than $10 \%$ deviation.

amounts of MGDG, DGDG and SQDG. There was a clear increase of DGDG $(20 \%)$ in $\mathrm{Cu}^{2+}$-treated cells, whereas MGDG and SQDG declined (29\% and 44\%, respectively) Table 2.

\subsubsection{Fatty acid composition}

We further analysed the total fatty acid composition of the $50 \mu \mathrm{M} \mathrm{Cu}^{2+}$-exposed cells. The proportion of linolenate (18:3) in fatty acids was lower in treated cells as compared to control cells (20.5\% instead of 25.8\%) Fig. 2. On the other hand, 16:0 and linoleate (18:2) were slightly higher (25.9\% instead of $23.6 \%$ and $47.0 \%$ instead of $44.1 \%$, respectively) Fig. 2.

When the lipids were analysed individually, we observed that the $\mathrm{Cu}^{2+}$ treatment did not affect the proportion of fatty acids within PE, PC, PI and DPG Fig. 3. In contrast, PG, DGDG, MGDG and SQDG showed an increase in 18:2 and a concomitant decrease in 18:3 Figs. 3 and 4p. In SQDG and $\mathrm{PG}, \mathrm{Cu}^{2+}$ treatment induced a strong enrichment in 16:0.

Table 2

Total polar lipid content of A. pseudoplatanus cells submitted for $5 \mathrm{~d}$ to $0.2 \mu \mathrm{M}$ (control) and $50 \mu \mathrm{M} \mathrm{Cu}{ }^{2+}$. Results are expressed as lipid mass and as percentage of total polar lipids. Results are the median of five independent experiments with less than $10 \%$ deviation. The data ranges of the five independent experiments are referred in brackets

\begin{tabular}{|c|c|c|c|c|c|}
\hline & $\begin{array}{l}\text { Control } \\
\left(\mathrm{mg} \mathrm{g}^{-1} \text { wet wt) }\right.\end{array}$ & $\%$ & $\begin{array}{l}50 \mathrm{mM} \mathrm{Cu}^{2+} \\
\left(\mathrm{mg} \mathrm{g}^{-1} \text { wet wt }\right)\end{array}$ & $\%$ & $\Delta$ Mass $(\%)$ \\
\hline$\overline{\mathrm{PC}}$ & $883.0(83.9)$ & 47.4 & $960.0(93.1)$ & 47.1 & +8.7 \\
\hline PE & $564.8(49.7)$ & 30.3 & $679.2(67.9)$ & 33.3 & +20.3 \\
\hline PI & $169.0(13.5)$ & 9.0 & $166.2(10.0)$ & 8.1 & -1.7 \\
\hline PG & $98.6(6.9)$ & 5.3 & $106.0(9.6)$ & 5.2 & +7.5 \\
\hline DPG & $41.0(3.2)$ & 2.2 & $29.2(2.2)$ & 1.4 & -28.9 \\
\hline Total phospholipids & $1756.4(157.2)$ & 94.3 & $1940.6(182.8)$ & 95.2 & +10.5 \\
\hline SQDG & $14.2(1.3)$ & 0.8 & $8.0(0.8)$ & 0.4 & -43.7 \\
\hline MGDG & $41.0(3.9)$ & 2.2 & $29.0(2.6)$ & 1.4 & -29.3 \\
\hline DGDG & $50.0(4.9)$ & 2.7 & $60.0(5.3)$ & 2.9 & +20.0 \\
\hline Total glycolipids & $105.2(10.1)$ & 5.7 & $97.0(8.7)$ & 4.8 & -7.8 \\
\hline Total polar lipids & $1861.6(167.3)$ & 100 & $2037.6(191.5)$ & 100 & +9.5 \\
\hline
\end{tabular}




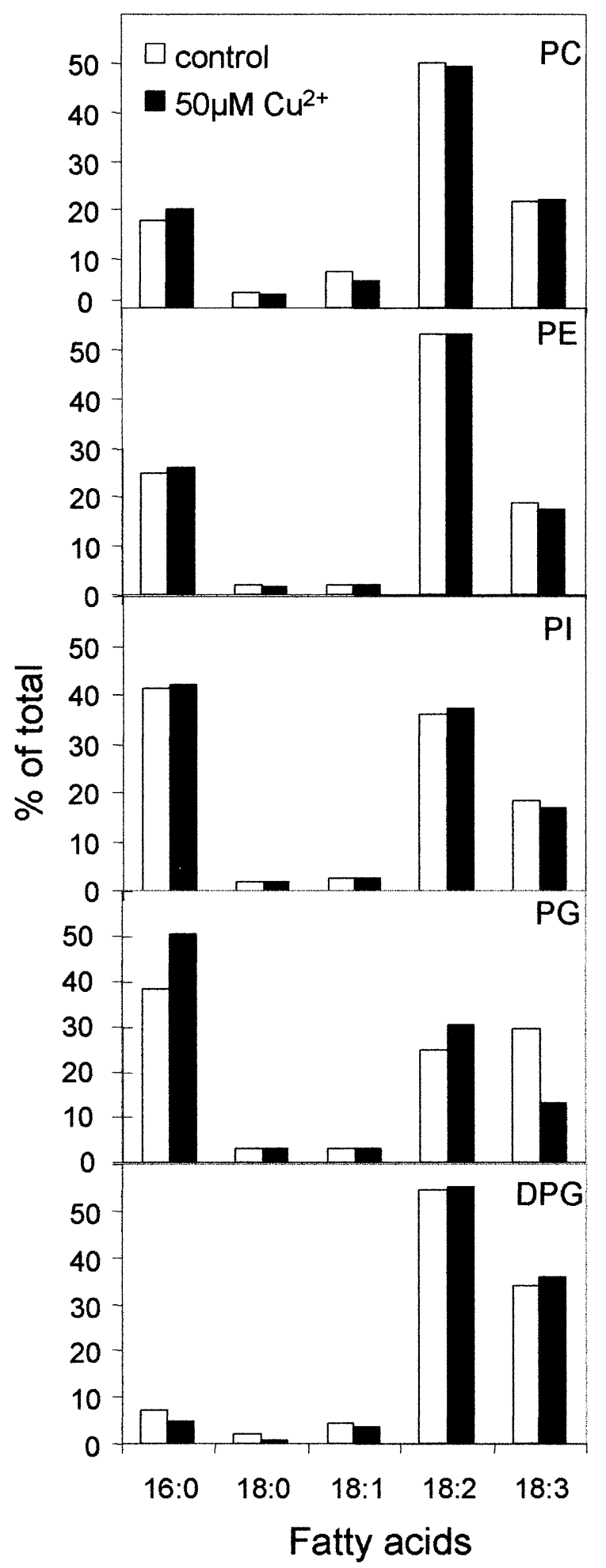

Fig. 3. Phospholipid fatty acid content of A. pseudoplatanus cells submitted for $5 \mathrm{~d}$ to $0.2 \mu \mathrm{M}$ (control) and $50 \mu \mathrm{M} \mathrm{Cu}^{2+}$. Results are the median of five independent experiments with less than $10 \%$ deviation.

\section{Discussion}

In the present work, we were able to analyse the effects of $\mathrm{Cu}^{2+}$ on plant metabolism under sub-lethal conditions, as shown by the reversible arrest of growth at a concentration of

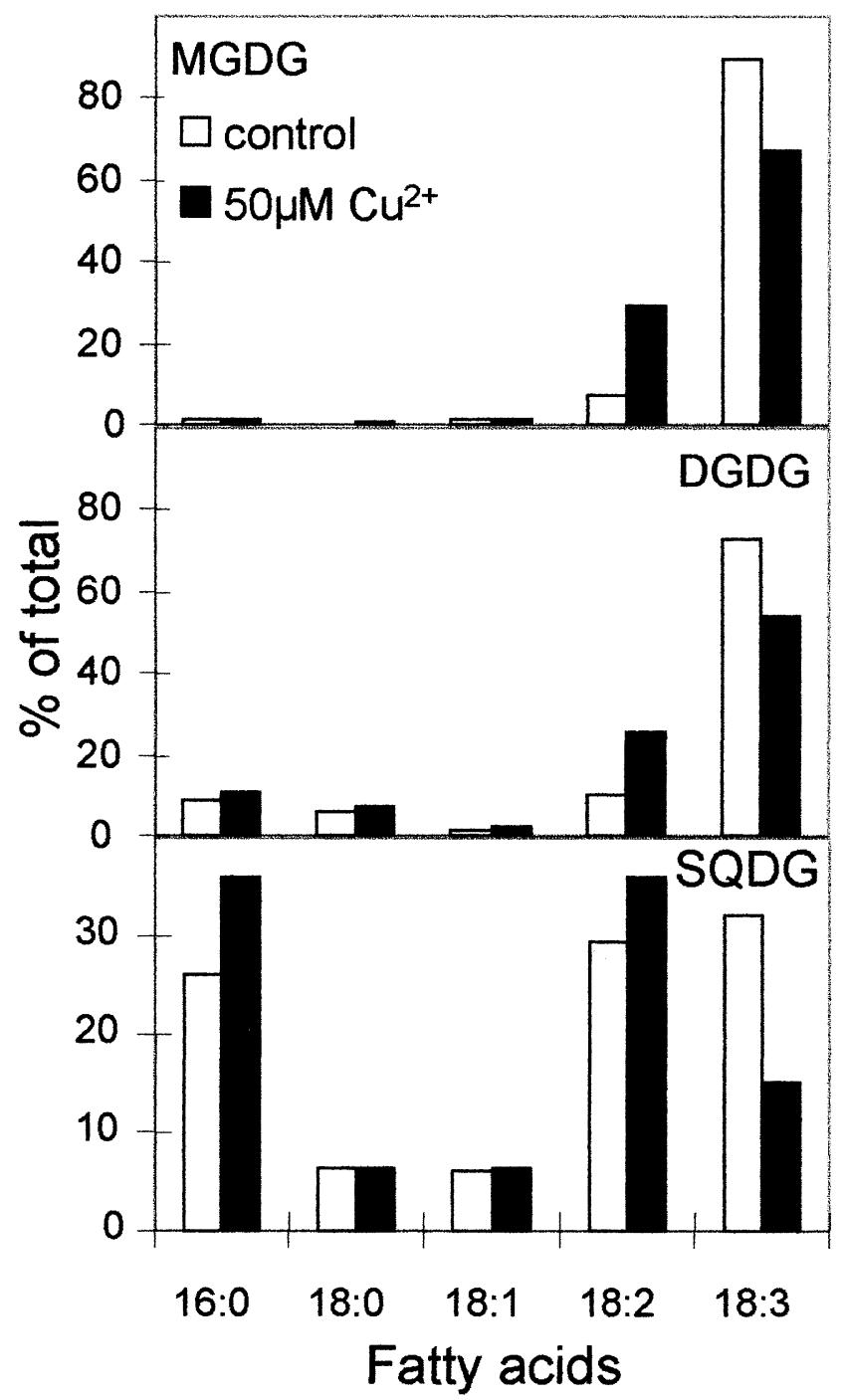

Fig. 4. Glycolipid fatty acid content of A. pseudoplatanus cells submitted for $5 \mathrm{~d}$ to $0.2 \mu \mathrm{M}$ (control) and $50 \mu \mathrm{M} \mathrm{Cu}^{2+}$. Results are expressed in percentage of total glycolipids. Results are the median of five independent experiments with less than $10 \%$ deviation.

$50 \mu \mathrm{M}$ copper. Under these conditions the arrest of growth was characterised by an accumulation of soluble sugars (sucrose, glucose and fructose) and phosphorylated hexoses, while starch was not affected. This is consistent with the fact that the carbon source was not limiting, since the medium was continuously renewed with more sucrose every $2 \mathrm{~d}$. Metabolism must be slowing down, in a context of decline of respiration due to a decrease of mitochondria [21] The fact that glucose increased in copper-treated cells without a concomitant proportional increase in glucose-6P suggests that glucokinase is not able to phosphorylate the excess of glucose, possibly due to saturation or partial inhibition. Interestingly, fructose phosphorylation was less affected as indicated by a marked increase in fructose-6P, which may reflect a preferential phosphorylation of fructose vs. glucose.

Several authors [17,25,26,32,33] have described $\mathrm{Cu}^{2+}$ mediated polar lipid degradation processes in plants, through increased lipooxygenase, lipase or peroxidation activities. In 
sycamore cells, polar lipid degradation has been described under conditions of carbon starvation [3,12]. This stress results in autophagic degradation of membranes accompanied by an accumulation of phosphocholine, a compound that cannot be metabolised as long as growth is stopped. In the present work, we observed that sub-lethal copper concentrations did not result in the accumulation of phosphocholine, consistent with the absence of decline of total polar lipids. On the other hand, lethal concentrations of $\mathrm{Cu}^{2+}(>100 \mu \mathrm{M})$ were characterised by a marked accumulation of phosphocholine and a concomitant decline of polar lipids (result not shown), suggesting that polar lipid degradation was occurring. These results suggest that lipid degradation may be a toxic effect of copper at high concentrations while sub-lethal concentrations do not produce lipid decrease and result in specific effects on lipid metabolism (see below).

A slight increase of phospholipids was observed in $\mathrm{Cu}^{2+}$ treated cells, mostly due to the major phospholipid PE. This could be a sign of extraplastidal membranes expansion associated to a greater cell volume, as reported by Pascal and Douce [24] in sycamore cells exposed to iron deprivation. Interestingly, De Vos et al. [7] observed that $\mathrm{Cu}^{2+}$-stress resulted in an increase of polar lipids in S. cucubalus cultivar tolerant to copper, while non-tolerant cultivars showed a decline of lipids when exposed to excess copper.

Although the total glycolipids (MGDG, DGDG and SQDG) concentration remained rather similar in both control and $\mathrm{Cu}^{2+}$-treated cells, we found differences in their proportions. MGDG declined markedly, as already reported by several authors [15,16,20] who attributed this effect to the differential specificity of galactolipase, which would preferentially degrade MGDG instead of DGDG. Ouariti et al. [20] observed a reduction of the content of both MGDG and DGDG. In contrast, in our work, sub-lethal $\mathrm{Cu}^{2+}$-treatment sycamore cells leads to increased DGDG level that is well correlated with the decrease in MGDG level, suggesting a conversion of MGDG to DGDG. Moreover, no galactosylglycerol was detected (not shown) suggesting that $\mathrm{Cu}^{2+}$ did not stimulate galactolipase activity.

The accumulation of DGDG in sycamore cells may originate from different pathways. First, DGDG could originate from the usual pathway of DGDG synthesis that involves two MDGD molecules in order to form DGDG and diacylglycerol (DAG) [11] This hypothesis is not consistent with the 1:1 stoicheometry observed for MGDG decrease vs. DGDG increase. Second, DGDG could originate from the direct galactosylation of MGDG with UDP-galactose through the recently discovered DGD2 pathway [13] or a similar pathway. In this context, UDP-galactose as well as phosphohexoses accumulated in A. pseudoplatanus cells submitted to 50 $\mu \mathrm{M} \mathrm{Cu}^{2+}$. Interestingly, Kelly and Dörmann [13] suggested that the DGD2 protein was involved in the synthesis of DGDG under stress conditions such as phosphate deficiency.

Regarding the synthesis of MGDG, A. pseudoplatanus is a C18 plant [23] and, therefore, has very little prokaryotic pathway. This implies that MGDG should originate from endoplasmic reticulum PC. One hypothesis is that MGDG is formed from lyso-phosphatidylcholine (lyso-PC) imported into the plastids [18,19] Akermoun et al. [1] demonstrated that one enzyme of this pathway, lyso-PC acyltransferase, is extremely sensitive to $\mathrm{Cu}^{2+}$-stress. As we did not observe a decrease of total plastid lipids, it is possible that the sublethal $\mathrm{Cu}^{2+}$-stress is not strong enough to achieve full inhibition of this enzyme or that an alternative pathway for plastid lipid biosynthesis from PC does occur (see [34].

The marked decrease of SQDG in $\mathrm{Cu}^{2+}$-treated cells can possibly reflect either a better galactosylation of DAG than sulfoquinovosylation or the inhibition of the enzyme responsible for the formation of SQDG.

The analysis of fatty acids permitted to document the effects of sub-lethal copper exposure on fatty acid elongation and desaturation. Interestingly, and in contrast to some reported studies [15,20], we only found fatty acid effects in the plastid lipids. In SQDG and PG our results show that $\mathrm{Cu}^{2+}$ triggered the accumulation of 16:0 fatty acids at the expense of C18 species. In these sub-lethal conditions, however, neither an inhibition of the chain elongation, nor an effect on the specificity of the acyl-ACP thioesterase seems likely since only two of the plastid lipids were affected. Smith et al. [28,29] suggested that $\mathrm{Cu}^{2+}$ induced a specificity change of the plastid located acyl-ACP transferase involved in the prokaryotic pathway. Even if A. pseudoplatanus cells have very little prokaryotic pathway, we cannot rule out this hypothesis.

Concerning fatty acid desaturation, some authors $[7,20]$ referred that while $\mathrm{Cu}^{2+}$ did not cause any effect on 18:0 concentration, 18:1 accumulated and 18:2 and 18:3 concentrations were reduced in all polar lipid species. These results reflect a general inhibition of fatty acid desaturation or a general degradation of unsaturated fatty acids. Our results are clearly different since the exposure to $50 \mu \mathrm{M} \mathrm{Cu}^{2+}$ only affected the fatty acids of plastid polar lipids. In fact, we show that in all plastid lipids (PG, SQDG, MGDG and DGDG), 18:2 accumulated and 18:3 decreased while the concentrations of 18:0 and 18:1 did not change. The decrease of 18:3 species through deacylase or peroxidation is not likely since no indication of peroxidation was observed and the 18:3 decrease is concomitant with a specific accumulation of 18:2 species. This same result was referred by Pascal and Dorne [23] in A. pseudoplatanus cells under iron deprivation stress and it was attributed to the possible existence of an iron centre in the $f a d 6$ and/or $f a d 7$ encoded fatty acid desaturases. Our results are consistent with a specific inhibition by $\mathrm{Cu}^{2+}$ of the fatty acid desaturation from 18:2 to 18:3, by interfering with the $\mathrm{fad} 6$ and/or $\mathrm{fad} 7$ encoded desaturases or associated proteins. In fact, two of the proposed mechanisms for $\mathrm{Cu}^{2+}$ inhibition of enzymes are by metal substitution or mercaptide formation with sensitive thiol groups $[6,32]$

Under the sub-lethal conditions herein described we found $\mathrm{Cu}^{2+}$ effects on mitochondria (decline in DPG, arrest of mitochondria biogenesis, enzyme induction [21,22]] and 
on plastids (DGDG synthesis and inhibition of 18:2 desaturation) that are clearly different than the effects reported by many authors under lethal $\mathrm{Cu}^{2+}$ concentrations. The reversible $\mathrm{Cu}^{2+}$-stress we report here may help clarify some basic questions such as how $\mathrm{Cu}^{2+}$ is transported towards cell organelles and how the cell metabolism is protected from deleterious effects of copper.

\section{Methods}

\subsection{Plant material}

Sycamore cells (A. pseudoplatanus L.) used in this study were grown at $20^{\circ} \mathrm{C}$ as a suspension in liquid nutrient media containing sucrose [5] The culture medium was kept at a volume of 0.31 and stirred continuously at $60 \mathrm{rpm}$. Control cells were grown with traces of $\mathrm{Cu}^{2+}(0.2 \mu \mathrm{M})$. In order to maintain a constant supply of $\mathrm{Cu}^{2+}$ for the control and treated cells, the appropriate culture medium were renewed every $48 \mathrm{~h}$. Under these conditions, the wet wt doubling time for control cells was 3.5-4 d. and the maximum density of sycamore cells was attained after $13-15 \mathrm{~d}$ as described by Pádua et al. [21] The cells wet wt was measured after straining culture aliquots through a glass-fibre filter. The cells dry wt was determined after dehydration for $8 \mathrm{~h}$ at $80^{\circ} \mathrm{C}$. Each experiment was repeated at least five times with cells originating from independent cultures.

\subsection{Carbohydrate measurements}

Sucrose, glucose and fructose were extracted from $100 \mathrm{mg}$ wet wt of sycamore cells submitted to $0.2 \mu \mathrm{M}$ (control) and $50 \mu \mathrm{M} \mathrm{Cu}^{2+}$ for $5 \mathrm{~d}$ and analysed according to Aubert et al. [3] Starch was measured as glucose equivalents after hydrolysis with amyloglucosidase as described by Aubert et al. [3] Quantification performed in a Beckman DU640 spectrophotometer. Each experiment was repeated at least five times with cells originating from independent cultures.

\section{3. ${ }^{31} P-N M R$ analysis}

Perchloric acid (PCA) extracts were prepared from $10 \mathrm{~g}$ of cells as described by Aubert et al. [3]. Spectra were obtained on a spectrometer (AMX 400) equipped with a 10-mm multinuclear probe tuned at 161.9 and $100.6 \mathrm{MHz}$ for ${ }^{31} \mathrm{P}-\mathrm{NMR}$. The deuterium resonance of ${ }^{2} \mathrm{H}_{2} \mathrm{O}(100 \mu \mathrm{l}$ added per ml of extract) was used as a lock signal. Conditions for ${ }^{31} \mathrm{P}-\mathrm{NMR}$ acquisition utilized $15-\mu$ s pulses $\left(70^{\circ} \mathrm{C}\right)$ at 3.6-s intervals and a sweep width of $8.2 \mathrm{kHz}$. Broad-band decoupling at $1 \mathrm{~W}$ during acquisition and $0.5 \mathrm{~W}$ during delay was applied using the Waltz sequence; the signal was digitized using 8000 data points zero-filled to 16,000 and processed with a $0.2 \mathrm{~Hz}$ line broadening. Spectra were referenced to methylene diphosphonic acid ( $\mathrm{pH} 8.9)$ at $16.38 \mathrm{ppm}$. The assignment of resonance of inorganic phosphate and soluble Pi-containing compounds to specific peaks observed on in vitro ${ }^{31} \mathrm{P}-\mathrm{NMR}$ spectra was carried out as described by Gout et al. [10] Identified compounds were quantified from the surface of their resonance peaks using fully relaxed conditions for spectra acquisition (pulses at 20-s intervals) as described elsewhere [2,10] Each NMR experiment was repeated at least five times with cells originating from independent cultures.

\subsection{Lipid measurements}

Lipids were extracted from $5 \mathrm{~g}$ wet wt of sycamore cells submitted to $0.2 \mu \mathrm{M}$ (control) and $50 \mu \mathrm{M} \mathrm{Cu}^{2+}$ for $5 \mathrm{~d}$ and analysed according to Douce et al. [8] Polar lipids were resolved by two-dimensional TLC [8] Lipids were identified by the chemical methods described previously $[4,12]$ The lipids thus obtained were trans-esterified and their methylated fatty acids were separated by gas chromatography after using Perkin Elmer autosystem XL with a BPX70, SGE column with a Flame Ionization Detector. Fatty acids were identified and quantified as described by Douce et al. [8] Each experiment was repeated at least five times with cells originating from independent cultures.

\section{References}

[1] M. Akermoun, E. Testet, C. Cassagne, J. Bessoule, Inhibition of the plastidial phosphatidycholine synthesis by silver, copper, lead and mercury induced by formation if mercaptides with the lyso-PC acyltransferase, Biochim. Biophys. Acta 1581 (2002) 21-28.

[2] S. Aubert, R. Bligny, R. Douce, NMR studies of metabolism in cell suspensions and tissue cultures, in: Y. Shachar-Hill, P. Pfeffer (Eds.), Nuclear Magnetic Resonance in Plant Biology, American Society of plant Physiologists, Rockville, 1996, pp. 109-154.

[3] S. Aubert, E. Gout, R. Bligny, D. Marty-Mazars, F. Barrieu, J. Alabouvette, F. Marty, R. Douce, Ultrastructural and biochemical characterisation of autophagy in higher plant cells subjected to carbon deprivation: control by the supply of mitochondria with respiratory substrates, J. Cell Biol. 133 (1996) 1251-1263.

[4] R. Bligny, R. Douce, Precise location of cardiolipin in plant cells, Biochim. Biophys. Acta 617 (1980) 254-263.

[5] R. Bligny, J.J. Leguay, Techniques of cell suspension culture, Methods Enzymol. 148 (1987) 3-16.

[6] M.A. Block, E. Maréchal, J. Joyard, Role of the plastid envelope in the biogenesis of chloroplast lipids, in: E.M. Aro, B. Andersson (Eds.), Regulation of Photosynthesis, vol. 11, Kluwer Academic Publishers, London, 2001, pp. 195-218.

[7] C.H.R. De Vos, W. Bookum, R. Vooijs, H. Schat, L. De Kok, Effect of copper on fatty acid composition and peroxidation of lipids in the roots of copper tolerant and sensitive Silene cucubalus, Plant Physiol. Biochem. 31 (1993) 151-158.

[8] R. Douce, J. Joyard, M.A. Block, A.J. Dorne, Glycolipid analyses and synthesis in plastids, in: J.L. Harwood, J.R. Bowyer (Eds.), Methods in Plant Biochemistry: Lipids, Membranes and Aspects of Photobiology, 4, Academic Press, San Diego, 1990, pp. 71-103.

[9] M. Droppa, G. Horváth, The role of copper in photosynthesis, Crit. Rev. Plant Sci. 9 (1990) 111-123.

[10] E. Gout, A.M. Boisson, S. Aubert, R. Douce, R. Bligny, Origin of the cytoplasmic $\mathrm{pH}$ changes during anaerobic stress in higher plant cells. Carbon-13 and phosphorous-31 nuclear magnetic resonance studies, Plant Physiol. 125 (2001) 912-925.

[11] J.W.M. Heemskerk, J.F.G.M. Wintermans, The role of the chloroplast in the leaf acyl-lipid synthesis, Physiol. Plant 70 (1987) 558-568. 
[12] E.P. Journet, R. Bligny, R. Douce, Biochemical changes during sucrose deprivation in higher plant cells, J. Biol. Chem. 261 (1986) 3193-3199.

[13] A.A. Kelly, P. Dörmann, DGD2, an arabidopsis gene encoding a UDP-galactose-dependent digalactosyldiacylglycerol synthase is expressed during growth under phosphate-limiting conditions, J. Biol. Chem. 277 (2002) 1166-1173.

[14] W. Maksymiec, Effect of copper on cellular processes in higher plants, Photosynthetica 34 (1997) 321-342.

[15] W. Maksymiec, R. Russa, T. Urbanik-Sypniewska, T. Baszynski, Changes in acyl-lipid and fatty acid composition in thylakoids of copper non-tolerant spinach exposed to excess copper, J. Plant Physiol. 140 (1992) 52-55.

[16] W. Maksymiec, R. Russa, T. Urbanik-Sypniewska, T. Baszynski, Effect of excess $\mathrm{Cu}$ on the photosynthetic apparatus of runner bean treated at two different growth stages, Physiol. Plant 91 (1994) 715-721.

[17] A.A. Meharg, Integrated tolerance mechanisms, constitutive and adaptive plant responses to elevated metal concentrations in the environment, Plant Cell Env. 17 (1994) 989-993.

[18] S. Mongrand, J. Bessoule, C. Cassagne, A re-examination in vivo of the phosphatidylcholine-galactolipid metabolic relationship during plant lipid biosynthesis, Biochem. J. 327 (1997) 853-858.

[19] S. Mongrand, C. Cassagne, J. Bessoule, Import of lysophosphatidylcholine into chloroplasts likely at the origin of eukaryotic plastidial lipids, Plant Physiol. 122 (2000) 845-852.

[20] O. Ouariti, N. Boussama, M. Zarrouk, A. Cherif, M.H. Ghorbal, Cadmium and copper-induced changes in tomato membrane lipids, Phytochemistry 45 (1997) 1343-1350.

[21] M. Pádua, S. Aubert, A. Casimiro, R. Bligny, Arrest of mitochondrial biogenesis in copper-treated sycamore cells, FEBS Lett. 398 (1996) 248-252.

[22] M. Pádua, S. Aubert, A. Casimiro, R. Bligny, H. Millar, D.A. Day, Induction of alternative oxidase by copper in sycamore cell suspensions, Plant Physiol. Biochem. 37 (1999) 131-137.
[23] N. Pascal, A.J. Dorne, Inhibition of fatty acid desaturation in sycamore cells deprived of iron, FEBS Lett. 253 (1994) 985-989.

[24] N. Pascal, R. Douce, Effect of iron deficiency on the respiration of sycamore (A. pseudoplatanus L.) cells, Plant Physiol. 103 (1993) $1329-1338$.

[25] S. Rama Devi, M.N.V. Prasad, Membrane lipid alterations in heavy metal exposed plants, in: M.N.V. Prasad, J. Hagemeyer (Eds.), Heavy Metal Stress in Plants. From Molecules to Ecosystems, Springer, Berlin, 1999, pp. 99-117.

[26] G. Sandmann, P. Böger, Copper-mediated lipid peroxidation processes in photosynthetic membranes, Plant Physiol. 66 (1980) 797-800.

[27] E. Skorzynska, T. Urbanik-Sypniewska, R. Russa, T. Baszynski, Galactolipase activity of chloroplasts in cadmium-treated runner bean plants, J. Plant Physiol. 138 (1991) 454-459.

[28] K.M. Smith, G.W. Bryan, J.L. Harwood, Changes in endogenous fatty acids and lipid synthesis associated with copper pollution in Fucus spp, J. Exp. Bot. 36 (1985) 663-669.

[29] K.M. Smith, G.W. Bryan, J.L. Harwood, Changes in the lipid metabolism of Fucus serratus and Fucus vesiculosus caused by copper, Biochim. Biophys. Acta 796 (1984) 119-122.

[30] A.L. Sommer, Copper as an essential element for plant growth, Plant Physiol. 6 (1931) 339-345.

[31] K.L. Stefanov, S.D. Pandev, K.A. Seizova, L.A. Tyankova, S.S. Popov, Effect of lead on the metabolism in spinach leaves and thylakoid membranes, Biol. Plant 37 (1995) 251-256.

[32] F. Van Assche, H. Clijsters, Effects of metal on enzyme activity in plants, Plant Cell Env. 13 (1990) 195-206.

[33] J. Vangronsveld, H. Clijsters, in: M.E. Farago (Ed.), Plant and the Chemical Elements. Biochemistry, Uptake, Tolerance and Toxicity, VCH Publishers, New York, 1994, pp. 150-177.

[34] J.P. Williams, V. Imperial, M.U. Khan, J.N. Hodson, The role of phosphatidylcholine in fatty acid exchange and desaturation in Brassica napus L. leaves, Biochem. J. 349 (2000) 127-133. 